EGU2020-18109

https://doi.org/10.5194/egusphere-egu2020-18109

EGU General Assembly 2020

(c) Author(s) 2021. This work is distributed under

the Creative Commons Attribution 4.0 License.

\title{
Significant changes in the magma dynamics of Stromboli steady- state volcano recorded by clinopyroxene crystals.
}

Chiara Maria Petrone ${ }^{1}$, Flavio Di Stefano ${ }^{2}$, Ralf Gertisser ${ }^{3}$, Silvio Mollo ${ }^{2,4}$, Simone Tommasini $^{5}$, Elisabetta Del Bello ${ }^{4}$, Daniele Andronico ${ }^{4}$, Piergiorgio Scarlato ${ }^{4}$, Pierpaolo Giacomoni ${ }^{6}$, and Massimo Coltorti ${ }^{6}$

${ }^{1}$ The Natural History Museum, Department of Earth Sciences, Cromwell Road, SW7 5BD London, United Kingdom (c.petrone@nhm.ac.uk)

${ }^{2}$ Dipartimento di Scienze della Terra, Sapienza-Università di Roma, P.le Aldo Moro 5, 00185 Roma, Italy

${ }^{3}$ Keele University, William Smith Building, Staffordshire, ST5 5BG, UK

${ }^{4}$ Istituto Nazionale di Geofisica e Vulcanologia, Via di Vigna Murata 605, 00143 Rome, Italy

${ }^{5}$ Dipartimento di Scienze della Terra, Università di Firenze, Via La Pira 4, 50121 Firenze, Italy

${ }^{6}$ Dipartimento di Fisica e Scienze della Terra, Università di Ferrara, Via Saragat 1, 44122 Ferrara, Italy

Steady-state volcanic activity implies equilibrium between the rate of magma replenishment and eruption of compositionally homogeneous magmas, lasting for tens to thousands of years in an open conduit system. The Present-day activity of Stromboli volcano (Aeolian Islands, Southern Italy) has long been recognised as typical of a steady-state volcano, with a shallow magmatic reservoir (highly porphyritic or hp-magma) continuously refilled by more mafic magma (with low phenocryst content or Ip-magma) at a constant rate and accompanied by mixing, crystallisation and eruption. The Ip-magma is erupted only during more violent explosive events (paroxysms), which usually occur at intervals of a few years. However, the two most recent paroxysms occurred at very short timescales on 3 July and 28 August 2019 offering the unique opportunity of obtaining crucial information on the current magma dynamics of Stromboli.

Albeit the plumbing system shows such uniformity, clinopyroxene phenocrysts exhibit marked chemical heterogeneities and complex textures caused by continuous Ip-hp magma mixing as well as antecryst recycling from different mush portions. The compositional zoning in clinopyroxene provides essential information on pre-eruptive magma dynamics, indicating multi-stage crystallization across the Ip-hp-reservoirs, where diopsidic compositions are markers of more primitive, high-T magmas injecting into shallow, low-T domains of the plumbing system. By comparing clinopyroxene texture, chemistry and residence times from the Present-day eruptions with the previous Post-Pizzo activity, we conclude that a distinct phase in the life of Stromboli volcano commenced after the violent 2003 paroxysm. Our observations suggest there are more efficient mechanisms of mush disruption and cannibalization, in which old diopsidic antecrysts are continuously remobilized and transported by the Ip-magmas permeating the mush. The disappearance of diopsidic recharge bands within augitic overgrowths indicates that over time, magmatic injections feeding the persistent Present-day activity are more intensively mixed and 
homogenized prior to eruption. 